\title{
The clinical role of nurse teachers within a Project 2000 course framework
}

\author{
Caroline Carlisle MSc BA RGN RM DN Cert Dip Couns RNT \\ Lecturer in Nursing, Department of Nursing, University of Liverpool, Liverpool
}

\author{
Susan Kirk MSc BNurs RGN RM RHV DN Cert \\ Research Associate, National Primary Care Research and Development Centre, \\ University of Manchester, Manchester
}

and Karen A. Luker PhD BNurs RGN RHV DN Cert

Professor of Community Nursing, Department of Nursing, University of Liverpool,

Liverpool, England

\begin{abstract}
CARLISLE C., KIRK S. \& LUKER K. A. (1997) Journal of Advanced Nursing 25, 386-395

The clinical role of nurse teachers within a Project 2000 course framework This paper reports on part of a national study that was conducted over a 3-year period (1991-1994). The overall aim of the study was to explore the changing role of the nurse teacher. Multiple methods of data collection were used, including a modified Delphi survey, a case study and telephone interviews. The sample included a wide variety of respondents (nurse teachers, midwife teachers, clinical nurses, health service managers and higher education lecturers). Findings in relation to the clinical role of the nurse teacher within a Project 2000 course framework are presented. This includes the nature of the clinical role, views on linking theory and practice, and potential barriers to the nurse teacher's clinical role. The future role of nurse teachers within the clinical area is discussed and this includes suggestions for the ways in which a nurse teacher's clinical commitment could be facilitated. Issues relating to the role of lecturer/practitioner are also highlighted.
\end{abstract}

\section{INTRODUCTION}

One of the main views expressed in a recent research project conducted amongst education and clinical managers was that 'nurses are expected and assumed to be competent' (Rapport \& Maggs 1994). This is not a controversial finding and indeed could be viewed as self-evident. It would, however, appear that the wider debate of the ways in which student nurses actually attain competency is one that generates substantial dissent between members of the nursing profession. At the core of this debate is the

Correspondence: Caroline Carlisle, Lecturer in Nursing, Department of Nursing, The Whelan Building, University of Liverpool, Liverpool L69 3BX, England. question of responsibility for teaching of clinical skills, which are necessarily a part of competency within the nursing profession. Unlike other academic disciplines, nursing is 'essentially vocationally specific' (Department of Health (DOH) 1994). The acquisition of both academic and clinical skills holds equal importance in the preparation of the competent practitioner, although it could be argued that the emphasis within Project 2000 (United Kingdom Central Council (UKCC) 1986) on theoretical achievement is pursued at the expense of clinical achievement.

Historically the teaching of clinical skills to students was accepted as a shared responsibility between clinical staff, the clinical nurse teacher and to a lesser extent the nurse teacher. Entry to clinical nurse teacher courses, 
however, ceased in the late 1980s and, although it was still possible at this time to achieve the qualification of clinical nurse teacher through such courses as the City and Guilds 730 , it was generally accepted within the profession that this role was disappearing. Since then there appears to have been varying views on precisely what the role of the nurse teacher is in relation to the teaching of clinical skills. Since the implementation of Project 2000, there have been numerous papers which exhort the profession to explore this in greater detail (Gerrish 1992, Charlesworth et al. 1992, Ferguson \& Jinks 1994). A number of research studies have addressed the teaching of clinical skills (Owen 1993, Hardiman 1993, Clifford 1993).

It would be simplistic to assume that issues regarding the teaching of clinical skills have escalated with the advent of diploma preparation for nurses. The controversial theory and practice debate has been active for many years. Interestingly, Dale (1994) even challenges the notion that there is a theory-practice gap, instead proposing that theory does exist within practice, but that it is different from the theory which exists in the classroom. Whatever stance we take on the theory-practice issue, it is generally accepted that nursing practice should take place within a framework of an appropriate knowledge base (DoH 1989, National Health Service Management Executive (NHSME) 1993), which should strive towards what is now termed evidence-based practice (DoH 1993). It is not surprising, therefore, that A Strategy for Nursing (DoH 1989) stated, as one of a range of strategic targets for nursing, that in future nurse teachers 'must be qualified or clinically credible in the area of practice they teach'. This has been reinforced more recently by The Future of Professional Practice document (UKCC 1994) which states that:

those who are educating the practitioners... must themselves be both clinically credible and knowledgeable about contemporary practice.

Nurse teachers are, therefore, having to give serious consideration not only to their role as educators but also to their clinical knowledge and expertise. There would appear to be no doubt that the added responsibilities of linking and integrating with higher education institutions have increased the academic workload of the nurse teacher (Luker et al. 1995). For many, the additional challenges of teaching at a higher educational level, becoming actively involved in research and publishing, has added to their workload. The question remains concerning the extent to which nurse teachers are involved, or wish to be involved, in the teaching of clinical skills to nursing students.

This also begs the question of whether nurse teachers view themselves as clinically competent and clinically credible. It may be that too much is being asked of one professional group to meet targets of achievement both in the academic domain with teaching and research priorities, and in the clinical arena where advances in treatment pose challenges even for those practitioners in full-time clinical practice. What is clear in the current climate is that 'the highest reported propensity to leave nursing recorded by IMS is amongst nurse teachers (40\%)' (Royal College of Nursing (RCN) 1995). A way forward must be sought to ensure that morale is maintained within this professional group.

\section{THE STUDY}

The data presented in this paper are part of a larger study examining the nurse teacher's role and preparation commissioned by the English National Board for Nursing, Midwifery and Health Visiting. The focus here is on the clinical role of the nurse teacher within a Project 2000 framework.

\section{Research methods}

Multiple methods were used to collect data between 1991 and 1994. The study employed a modified Delphi technique (Dalkey \& Helmer 1963), which involved distributing postal questionnaires to a panel of experts. The Delphi technique was modified by using random sampling and by using focus-group interviews between the two questionnaire rounds. The focus groups explored data from the first questionnaire in more depth, and the qualitative data derived from the focus groups were used in the design of the second questionnaire. The study also employed a case study, which was conducted throughout the lifetime of the project at one site that was at the forefront of Project 2000 implementation. A telephone interview survey was also conducted with a subsample of nurse educationalists and nurse teachers who had been qualified for 4 years or less.

\section{Sampling}

Nurse teachers were randomly sampled through the use of the database held by the UKCC $(n=600)$. Other groups in the sample, namely specialist nurses (e.g. health visitor lecturers), clinical nurses, health service managers, teacher education lecturers and link lecturers from higher education, were purposively sampled using factors such as geographical region and clinical speciality. Representation was achieved from all the institutions conducting teacher preparation courses in 1990-91 and from all the Project 2000 higher educational link institutions (1991) who had responded to the request for information. Table 1 details the response rates for the study.

\section{Research instruments}

The design of the questionnaires employed within the Delphi study was informed by a number of sources. The extensive background literature available on nurse 
Table 1 Response rates for the study

\begin{tabular}{lcc}
\hline Stage & Number & Percentage \\
\hline Case study questionnaire & 39 & $68 \cdot 0$ \\
$\begin{array}{l}\text { Case study interviews } \\
\text { Modified Delphi study first } \\
\quad \text { questionnaire }\end{array}$ & 516 & $100 \cdot 0$ \\
$\begin{array}{l}\text { Modified Delphi study focus-group } \\
\text { interviews }\end{array}$ & 34 & $63 \cdot 6$ \\
$\begin{array}{l}\text { Modified Delphi study final } \\
\text { questionnaire }\end{array}$ & 356 & $71 \cdot 3$ \\
Telephone interview survey & 54 & $89 \cdot 0$ \\
\hline
\end{tabular}

education was obtained, and up-to-date trends and issues were also highlighted by attendance at key groups and committees. The design was also informed by the data obtained at the case study site, where the real-life experiences of nurse teachers provided a vital source of fundamental issues and potential trends. The first questionnaire collected information regarding the characteristics of the sample. Open and closed questions and Likert scales were used to collect data regarding respondents' attitudes to particular issues. The intermediate focus-group interviews employed a semi-structured interview guide, the overall design of which enabled the exploration in greater depth of themes which arose from the first questionnaire of the Delphi study. The final questionnaire asked sample members to assess issues identified from the earlier stages of the research using a series of linear analogue scales. The scale descriptors chosen were the probability and desirability of certain events occurring within a 5-year timescale. The item pool was developed from the previous findings of the research and ensured that both majority and minority opinions were captured.

The telephone interviews utilized a structured interview schedule and comprised mainly fixed-choice response questions which included the use of Likert scales. One of the aims of these interviews was to gain further information in relation to role change and clinical responsibilities.

\section{Data analysis}

All data, with the exception of the focus group and case study interviews, were analysed using the Statistical and Presentation Software Systems Program (SPSSx). The data from the final questionnaire regarding the relative probability and desirability of each question were recoded to form two new variables, probability and desirability. For the purposes of this study a change was identified as being 'probable' if at least $70 \%$ of the respondents had rated it in this way. This criterion was applied to all the variables. Non-parametric statistics (chi-square, phi/Cramer's V) were used to investigate relationships between some key demographic variables and the opinions of sample members.
The focus group and case study interviews were taperecorded and transcribed verbatim for analysis. The analysis followed Stewart \& Shamdasani's (1990) structure of data making, which involved unitizing, sampling and recording. Content analysis, involving open-coding (Strauss \& Corbin 1990), was also incorporated to assist in the discovery of categories and themes which linked with the main aims of the study.

The data reported in this paper have been obtained by multiple methods. Where it is not explicitly stated in the text from which stage/method the data have been derived, a key is used, i.e. CSQN, case study questionnaire; CSI, case study interviews; FGI, focus-group interviews; QN1, first questionnaire of the modified Delphi study; QN2, final questionnaire of the modified Delphi study; TI, telephone interviews.

\section{FINDINGS}

The study explored the nature and changes related to the nurse teacher's clinical role and also issues which linked in with the concept of the theory-practice gap. Further information was also sought which explored potential future strategies for the clinical responsibilities of nurse teachers.

\section{The nature of the clinical role}

The final questionnaire explored the probability and desirability of the changes in the future role of the nurse teacher in the clinical area. As can be seen from Table 2, a number of changes are seen to be highly probable as well as highly desirable. These changes include the role of the teacher in educational audit, the facilitation of clinicians' teaching role and professional development, and acting as a resource person or adviser to clinical staff.

Table 3 illustrates those changes that are seen as probable by less than $70 \%$ of the sample, and it is noteworthy that these include working with students providing direct patient/client care, believed to be probable by only $58 \cdot 1 \%$ $(n=344)$ of respondents, and teaching students clinical skills in the practice area, seen as probable by only $56.9 \%$ $(n=346)$. There are, however, a large number of respondents who see these changes as desirable, $80 \cdot 3 \%(n=350)$ and $82 \cdot 1 \%(n=351)$, respectively (Table 3$)$. It would also appear that the sample see neither an increase or decrease in the clinical role as probable, with $54.4 \%(n=342)$ of respondents believing it probable that the role will increase and $48.0 \%(n=342)$ believing it probable that it will decrease (Table 3). There is, however, an important indicator in the respective desirability of a future clinical role. The majority $(82 \cdot 7 \%, n=347)$ of the respondents state that it would be desirable for the nurse teacher to have an increased clinical role, with only $16 \cdot 5 \%(n=346)$ believing it desirable that the role should decrease (Table 3 ). 
Table 2 Changes in the nurse teacher's clinical role given an overall rating as probable by $70 \%$ or more of the sample with the respective desirability of the response (QN2)

\begin{tabular}{lll}
\hline Role change & $\begin{array}{l}\text { Probability } \\
(\%)\end{array}$ & $\begin{array}{l}\text { Desirability } \\
(\%)\end{array}$ \\
\hline $\begin{array}{l}\text { Nurse teachers will continue to } \\
\text { audit clinical learning } \\
\text { environments }\end{array}$ & $87 \cdot 3$ & $92 \cdot 0$ \\
$\begin{array}{l}\text { Nurse teachers will faciliate } \\
\text { clinical staff in their teaching role }\end{array}$ & $86 \cdot 2$ & $98 \cdot 0$ \\
$\begin{array}{l}\text { with students } \\
\text { Nurse teachers will act as a } \\
\text { resource person for clinical staff }\end{array}$ & $83 \cdot 3$ & $96 \cdot 0$ \\
$\begin{array}{l}\text { The main contributions to the } \\
\text { teaching of nursing practice will } \\
\text { be made by clinical staff } \\
\text { employed by hospital and } \\
\text { community units }\end{array}$ & $81 \cdot 8$ & $67 \cdot 2$ \\
$\begin{array}{l}\text { There will be an increased demand } \\
\text { for nurse teachers to facilitate the } \\
\text { professional development of } \\
\text { clinical staff }\end{array}$ & $80 \cdot 8$ & \\
$\begin{array}{l}\text { Nurse teachers will experience } \\
\text { increasing difficulty in } \\
\text { maintaining their clinical } \\
\text { credibility with clinical staff }\end{array}$ & & \\
\hline
\end{tabular}

Table 3 Changes in the nurse teacher's clinical role given an overall rating as probable by less than $70 \%$ of the sample with the respective desirability of the response (QN2)

\begin{tabular}{lll}
\hline Role change & $\begin{array}{l}\text { Probability } \\
(\%)\end{array}$ & $\begin{array}{l}\text { Desirability } \\
(\%)\end{array}$ \\
\hline $\begin{array}{l}\text { A greater number of nurse teachers } \\
\text { will work as lecturer-practioners, } \\
\text { having a patient/client caseload }\end{array}$ & $61 \cdot 5$ & $76 \cdot 7$ \\
$\begin{array}{l}\text { Nurse teachers will work with } \\
\text { students in providing direct } \\
\text { patient/client care in the } \\
\text { practice area }\end{array}$ & $58 \cdot 1$ & $80 \cdot 3$ \\
$\begin{array}{l}\text { Nurse teachers will teach students } \\
\text { clincal skills in the practice area }\end{array}$ & $56 \cdot 9$ & $82 \cdot 1$ \\
$\begin{array}{l}\text { Nurse teachers will have an } \\
\text { increased clinical role }\end{array}$ & $54 \cdot 4$ & $82 \cdot 7$ \\
$\begin{array}{l}\text { Nurse teachers will have a } \\
\text { decreased clinical role }\end{array}$ & $48 \cdot 0$ & $16 \cdot 5$ \\
\hline
\end{tabular}

Clinical nurses, managers and teacher educationalists were found to more frequently regard it as improbable that nurse teachers would in future teach students clinical skills in the practice area than the other sample groups $\left(\chi^{2}=14 \cdot 60 ; \mathrm{df}=5 ; P=0 \cdot 01 ;\right.$ Cramer's $\left.\mathrm{V}=0.21 ; n=346\right)$. Clinical nurses were also found to more frequently regard it as improbable that nurse teachers would in future work with students in providing direct patient/client care $\left(\chi^{2}=\right.$ 14.86; $\mathrm{df}=5 ; P=0 \cdot 01$; Cramer's $\mathrm{V}=0 \cdot 20 ; n=344$ ).

The length of time individuals had been qualified as teachers was found to be associated with their assessment of the probability of nurse teachers teaching students clinical skills in the practice area, with those teachers who had been qualified for less than 5 years being found to more frequently view this as a probable change $\left(\chi^{2}=\right.$ 7.67 with Yate's correction; $\mathrm{df}=1 ; P=0 \cdot 006 ; \Phi=0 \cdot 20 ; n=$ 233). Another key variable that was found to be associated with the response to this issue was that of the relationship between the nurse education institution and the higher education institution. Those individuals where the relationship was one of full relocation into higher education were found to more frequently view it as improbable that nurse teachers in future will teach students clinical skills $\left(\chi^{2}=8.22\right.$ with Yate's correction; $\mathrm{df}=$ $1 ; P=0 \cdot 004 ; \Phi=0 \cdot 20 ; n=237)$. However, the values of phi and Cramer's V indicate that these are relatively weak relationships.

The results regarding the nature of the nurse teacher's role in the clinical area reflect the findings of the focus group interviews, where there was a general consensus of opinion that the role of the teacher in the clinical area need not entail the actual delivery of patient/client care. The term 'link' teacher was consistently used in all focus groups, but this link role was described more in terms of a facilitator and resource. The point was made, however, that this did not mean that nurse teachers did not want to be involved in the delivery of care, but it was felt that there was a number of barriers to interpreting and implementing the concept of link ward in this way. One teacher found that education managers were perfectly clear in their own mind as to what the role should entail:

I actually had it said to me that I was no longer a nurse, I was a teacher now and that my role in the clinical area was as an education officer and facilitator.

\section{Resistance}

Teachers who did attempt to incorporate care delivery within their link area met a great deal of resistance, not only from education managers but also from their nurse teacher colleagues and the ward staff. They believed that their peers felt threatened by their attempts to remain clinically credible, and the ward staff felt they had come to 'spy' on them. Service managers were also less than welcoming at attempts by nurse teachers to practice. A community nurse teacher who approached a manager with regard to taking on a clinical caseload was told by the manager that he 'wasn't prepared to let me touch his clients' (FGI).

All the teachers at the case study site had a link teacher 
role that largely entailed being an educational adviser/consultant. For some teachers this was their main clinical role:

The role has changed to a more supportive and advisory capacity, particularly in relation to student assessment.

$(\mathrm{CSQN})$

It has become more advisory, bringing knowledge of educational changes and rationale to the clinical area instead of so much time working with a student.

(CSQN)

It is interesting, however, to note the results from the telephone interviews, when nurse teachers were asked for their views on the main source of job satisfaction for them. Only three $(8 \cdot 3 \%)$ respondents cited clinical teaching with students as the main source of job satisfaction (Table 4).

Less than $70 \%$ of respondents in the final questionnaire rated it as probable that nurse teachers will in future work with students in providing direct patient/client care in the practice area (Table 3). The reality of the current clinical role for nurse teachers would appear not to include the delivery of nursing care to patients/clients. This was also the case for the respondents in the telephone interviews, with $22(61.1 \%)$ nurse teachers stating that their main role with students in the clinical area was in making supportive visits (Table 5).

\section{Supportive}

At the case study site the teachers reported that their role with students was also largely that of making supportive visits, as lack of time prevented them from having a more extensive role as these extracts from the data show:

I cannot get out to the wards to teach, only to visit and say hello.

(CSQN)

We do have the odd nip out and say how are you doing? Is everything OK? And we hope to god it is because we haven't got any time to spare them.

(CSI: 054)

Some teachers noted that their clinical role in relation to students was one of a 'troubleshooter' in that they would only tend to visit students in response to clinical staffs' concerns regarding the student's progress. They were

Table 4 Nurse teachers' views on their main source of job satisfaction $(n=36)(\mathrm{TI})$

\begin{tabular}{lcr}
\hline Main source & Number & $\%$ \\
\hline Teaching contact with students & 24 & $66 \cdot 7$ \\
Influencing the development of & 5 & $13 \cdot 9$ \\
professional practitioners & & \\
Clinical teaching with students & 3 & $8 \cdot 3$ \\
Other & 4 & $11 \cdot 1$ \\
Total & 36 & $100 \cdot 0$ \\
\hline
\end{tabular}

therefore visiting mainly the 'weak or those not coping' (CSI: 048).

Insufficient time resulted in some teachers using the telephone to perform their clinical role:

For those on the community it's a phone call certainly for the hospital it's easier.

(CSI: 05)

I wish I could say that I visit my link wards regularly but I don’t. It's a phone call now.

(CSI: 048)

Although the majority of respondents in the telephone interviews were not involved in the delivery of patient care either as a practitioner or as a teacher of clinical skills, they do, however, view themselves as safe and efficient members of clinical staff $(83 \cdot 3 \%, n=30)$.

It is noteworthy, however, that when asked this question during the interview many of the respondents qualified their answer by stating it would very much depend on the level of responsibility they had. So, for example, to go onto a ward and 'take charge' would not be something they felt able to do, but they may feel safe and efficient to give patient care in a position of less responsibility.

The perceptions of the respondents with regard to who would actually be responsible for teaching clinical skills to students and facilitating them in linking theory to practice was examined in greater detail.

\section{Linking theory and practice}

Respondents in the focus-group interviews believed that one important role for the nurse teacher was that of integrating the theory from a wide range of disciplines to the practice of nursing. This integration is, however, done on a purely theoretical basis, with the majority of nurse teacher participants stating that their actual clinical practice was extremely limited if it existed at all:

the school is having less input into the wards... nurse teachers are being asked to teach about nursing practice in areas that they might not have worked in for a long time.

Table 5 Nurse teacher's main role with students in the clinical area $(n=36)(\mathrm{TI})$

\begin{tabular}{lcc}
\hline Main role & Number & $\%$ \\
\hline Making supportive visits & 22 & $61 \cdot 1$ \\
Working with students delivering patient & 7 & $19 \cdot 4$ \\
$\quad$ care & 4 & $11 \cdot 1$ \\
Monitoring academic progress & 1 & $2 \cdot 8$ \\
Demonstrating specific clinical skills & 2 & $5 \cdot 6$ \\
No role & & \\
\hline
\end{tabular}


There was consensus on the belief that pre-registration students needed help to apply the theory to practice and cannot just be left to draw links for themselves:

whilst they [Project 2000] students recognize the importance of it [theory] they can't grasp the depth or the level to integrate it into practice.

Nurse teachers in the focus groups considered their role was not to teach clinical skills; this was seen to be the job of the clinical experts at ward level. This view was also expressed at the case study site:

it is more useful for them [Project 2000 students] to use a member of the clinical staff who are the clinical experts as their role models.

The clinical nurse has both the clinical knowledge and the credibility and now also the teaching skills.

(CSQN: 033)

This was consistent with the findings of the first questionnaire in the modified Delphi study, where only $2.4 \%$ (10) of respondents had stated that the nurse teacher was the most appropriate person to teach in the clinical area (Table 6). Instead it was seen either as a joint responsibility with clinical nurses $(242,57 \cdot 9 \%)$ or as the responsibility of clinical nurses only $(161,38 \cdot 5 \%)$ (Table 6$)$.

Some teachers at the case study site were eager to transfer the responsibility for the teaching of clinical skills to clinical nurses. They considered that this was appropriate now that this role had been written into the job descriptions of clinical staff. Clinical nurses were seen also being prepared for this role through English National Board (ENB) 998 courses.

\section{Quality of learning environment}

However, some teachers did express concerns regarding the quality of the clinical learning environment, both in terms of the time available to clinical nurses for teaching clinical skills and with regard to whether clinical staff actually taught students the correct techniques (and the

Table 6 The most appropriate teacher in the clinical area (nurse teachers, clinical nurses, teacher educationalists, specialist nurse teachers) $(n=418)$ (QN1)

\begin{tabular}{lrr}
\hline Individual & Number & $\%$ \\
\hline Both clinical nurse and nurse teacher & 242 & $57 \cdot 9$ \\
Clinical nurse & 161 & $38 \cdot 5$ \\
Nurse teacher & 10 & $2 \cdot 4$ \\
Other & 5 & $1 \cdot 2$ \\
Missing & 4 & - \\
Total & 418 & $100 \cdot 0$ \\
\hline
\end{tabular}

implications of this when the Project 2000 students themselves became the mentors):

Do the wards always teach correctly? Do the wards always have the time to teach these practical skills?

(CSI: 05)

We assume that they're being taught the correct dressing technique out on the wards by the clinical experts. But quite often the clinical experts have developed their own safe methods... but it's only with the proper initial grounding in basic techniques that you can deviate.

(CSI: 054)

Many nurse teachers felt that lip-service was being paid to the educational approach of reflective practice:

how are the students supposed to make these links between theory and practice? What are we doing to help them? I'm not sure we are doing anything at the moment.

we are expecting novice students to be able to do that [link theory and practice] with no facilitation whatsoever.

The nurse teachers at the case study site were concerned about the adequacy of the clinical skills acquired by Project 2000 students and the balance between theory and practice in the course:

I feel we have given them the knowledge but forgotten to show them what to do with it.

(CSI: 043)

I do feel the theory has taken over and left nursing as second best, and we're doing a nursing course and nursing is very much hands on and dependent upon skills.

(CSI: 048)

\section{Knowledgeable doer}

The development of the 'knowledgeable doer' was a major concern for the focus-group participants. One nurse teacher spoke of the 'quantum leap into practice' that Project 2000 students make with the hopeful expectation on the part of nurse teachers that the theory was 'going to suddenly click into place'. A teacher at the case study site feared that the teachers' reduced role in the clinical area may have widened the theory-practice gap:

Nurse teachers have got to be really careful that they don't remove themselves from what is the art of nursing... we were trying to break down the theory-practice gap and yet we haven't really, and that's one of the things that I thought might happen with Project 2000. Maybe it's even wider?

(CSI: 004)

The teaching of nursing practice was explored in the final questionnaire of the modified Delphi study. The results here emphasized the view that nurse teachers were 
not seen as clinically credible, with $80 \cdot 3 \%(n=345)$ of the respondents stating that nurse teachers would experience increasing difficulty in maintaining their clinical credibility with clinical staff (Table 2).

\section{Barriers to the clinical teaching role}

Most nurse teachers attending the focus-group interviews felt that they were unable, due to pressure of academic work, to spend regular and lengthy periods of time in the ward setting, even if they wished to do this. Lack of time was also noted as a barrier to clinical contact at the case study site:

time is short and if you get onto the clinical area now it's almost a miracle, even those that want to.

Clinical teaching is opportunistic if at all. Time only allows for brief visits to see students.

(CSQN)

The college had attempted to address this problem by appointing a 'placement visitor' who was an experienced ward sister. This person was to visit all students on practice placements during one part of the common foundation programme and assess how the students were coping with their placements, reporting any problems back to the teachers. As one teacher noted 'it's taken a burden off me really' (CSI: 029).

It was apparent that teachers did not view their clinical role as being a priority and that they also perceived that the college's emphasis was on the fulfilment of their classroom role:

I suppose on traditional courses visiting students on placements was a necessity but that was the first thing to go when other things came up... this has taken on a lesser priority.

(CSI: 037)

Time put aside for clinical work usually gets encroached because it's seen as less important... if I'm really honest I don't place enough importance on it.

(CSI: 004)

The nurse teachers attending the focus groups felt they did not possess up-to-date clinical skills and therefore lacked clinical credibility in the practice setting:

There is no way I can now say I'm an expert in any area... I don't do enough to say I'm a clinical expert.

\section{Up-to-date skills}

Clinical nurses agreed that the nurse teachers did not possess up-to-date skills. They felt that it was unfair on nurse teachers that they were being asked to teach nursing practice when they did not have up-to-date experience. Nurse teachers, although they had academic knowledge, felt in the current climate unable to practise in the clinical area in a credible role. The clinical nurses, although clinically credible, felt insecure about the expectation that they should link specific academic subject theory to practice.

A number of teachers expressed the view that they have a lack of confidence in their clinical skills. On first entering nurse teaching, many of the teachers had worked as an 'unqualified teacher' within a college of nursing/midwifery and this was seen to be the beginning of a steady deskilling process of their clinical skills:

by the time you eventually got on a teaching course you didn't know whether you were fish or fowl because you'd been through the system that had kind of deskilled you in your area.

When qualified, however, a number of teachers felt that the major reason they did not attempt to practise in their link ward was simply that it was not in their area of expertise. It was not unusual for a nurse teacher's past clinical speciality to be ignored when he or she was allocated a clinical area with which to link. Indeed this situation in a number of cases stretched back to a nurse teacher's initial recruitment as a teacher, this recruitment being made on the basis of an interest and flair for teaching rather than a need for teachers within a particular clinical speciality. Some respondents eloquently expressed their feelings of loss at not practising as a nurse:

I didn't want to leave the clinical area, but the profession told me I had to... my heart is still out in the clinical area... there was a focus there we could have worked on, but it doesn't exist any more.

I think I went through a grieving process, in fact I know I did. I found it very, very hard.

\section{Theory and practice links}

There are also issues of linking theory to practice in community settings. Few teachers in this study appeared to have a community qualification in spite of Project 2000's emphasis on this area (QN1: $36,10 \cdot 8 \%$; CSQN: $5,12 \cdot 8 \%$ ). It would seem, therefore, that few nurse teachers have the specific knowledge required for this specialist area. The work conducted at the case study site suggested that teachers experience difficulties in visiting community placements both because of their lack of expertise in this area and because of the travelling involved.

It is perhaps not surprising that the majority $(94 \cdot 7 \%, n=$ 342 ) of the sample in the final questionnaire felt it desirable to develop strategies to ensure that the clinical expertise/experience of the nurse teacher corresponds with their clinical teaching/liaison role. 


\section{THE WAY FORWARD}

This paper has explored a number of potential changes in the nurse teacher's future clinical role and has looked at levels of probability and desirability in relation to these changes. Although findings related to the exploration of the theory-practice gap have already been presented, it was thought necessary to examine the views of the sample in relation to the overall future clinical role of nurse teachers.

This topic was explored in depth within the focus group interviews. There were suggestions that, in future, clinicians who wished to become nurse teachers should always retain a clinical commitment, part of that commitment being primarily as a practitioner and not as a teacher:

teachers need to go native, as they say, once again and go back to their roots almost. As a nurse first, and a teacher second.

The 'link' ward was not seen to be an appropriate way forward. All three focus groups expressed the view that the way a nurse teacher's role on a link ward was utilized was very much up to the individual teacher. It was felt that the role was a rather nebulous one and often meant that it occurred only if the teacher could manage 'a few hours here or there'.

When asked to provide a vision for the future, it was noteworthy that only a minority of the participants within the groups felt able to state clearly what the future role of nurse teachers should be. One group participant commented:

If we have said clinical skills are not what we are here to teach anymore... then I think we have to very clearly redefine our role.

(FGI)

\section{Main suggestions}

Two main suggestions were discussed within the focus groups, that of retaining some sort of clinical commitment and the structure in which this could take place; and the development of the role of lecturer/practitioner (LP). It was

Table 7 Factors that hinder the development of the lecturerpractitioner role (nurse teachers) $(n=36)$ (TI)

\begin{tabular}{lcr}
\hline Factor & Number & $\%$ \\
\hline Conflict between education and service & 11 & $30 \cdot 6$ \\
Organization and management & 8 & $22 \cdot 2$ \\
$\quad$ difficulties & 7 & \\
Lack of funding & 6 & $19 \cdot 4$ \\
Insufficient time & 4 & $16 \cdot 7$ \\
Other & 36 & $11 \cdot 1$ \\
Total & & $100 \cdot 0$ \\
\hline
\end{tabular}

thought that teachers should be facilitated to spend at least 1 day per week in the clinical area. It was pointed out that this time should not primarily be for teaching students but for the clinical development of the teacher as a clinical nurse. A contractual agreement between education and service managers was highlighted as an important aspect of this development, in order to avoid the problems of which budget would actually pay for the nurse teacher's time when she or he was giving service in the clinical area:

until recently we had managers who carried the education budgets so the service managers actually were involved in paying the salaries of the teachers, which was why we could be drawn out of class and into the clinical area.

Opinion varied within the groups on the actual structure of the LP role. In the main, however, the LP role was seen as a 50/50 split between academic and clinical responsibilities. It was also stressed that the LP should have a clinical caseload and teach the related module within the theoretical programme.

It is interesting to note, however, that in the final questionnaire the respondents did not see it as particularly probable $(61.5 \%, n=343)$ that a greater number of nurse teachers would work as LPs, with a patient/client caseload, although it was viewed as a desirable change $(76 \cdot 7 \%, n=$ 346) (Table 3).

Given that the LP role had been highlighted in the focusgroup interviews, it was important to explore whether there could be any factors which could hinder the development of the role. The nurse teacher respondents in the telephone interviews were therefore asked to comment on this issue. It is interesting to note that conflict between education and service was the response cited most often by the sample $(11,30 \cdot 6 \%)$ with eight $(22 \cdot 2 \%)$ teachers stating the problem of organization and management difficulties as an inhibiting factor to the future of the role (Table 7).

\section{DISCUSSION}

The unprecedented rate of change with which nurse teachers are having to cope has without doubt affected their perceptions of their future role. The impact of contextual issues on nurse education research is one that has been emphasized in numerous studies (Bedford et al. 1993, White et al. 1993, Jowett et al. 1994).

It was not seen as probable that nurse teachers would work with students in providing direct patient/client care or in teaching students clinical skills in the practice area. It was seen as probable that the main contributions to the teaching of nursing practice would be by clinical staff employed by hospital and community units. It may be that nurse teachers feel the status quo will prevail and their current role as one which appears not to include the 
teaching of clinical skills will continue. This lack of nurse teachers' involvement in clinical teaching and direct care giving following Project 2000 is one which supports the findings of other studies (Crotty 1993, Jowett et al. 1994).

It is interesting to ask, however, how realistic it will be in the future for clinical staff employed by hospital and community units to be afforded the time to give to the teaching of Project 2000 students. Clinical staff within the new market-led health service, with the potential for higher levels of autonomy they have within trusts, may well not see the education of pre-registration nursing students as a justifiable priority or responsibility. Reducing the caseload of community health care professionals, for example, in order to meet the educational needs of students may no longer be possible in the future. The time taken to teach students may also be seen by purchasers as encroaching on clinical commitments, and payment for clinical placements may come higher on the agenda of provider institutions.

The desirable future role highlights the nurse teacher as having an increased role in the clinical setting, which involves teaching clinical skills and working alongside students providing patient/client care. So although the future appears not to hold the prospect of patient/client care giving, the respondents express a desire that it should, although it could be questioned whether there was some element of 'political correctness' in expressing a desire to have a clinical role.

\section{Teachers' dilemma}

Debate has extended over a number of years as to whether nurse teachers should act as a support for clinical staff in their clinical teaching role (Osborne 1991, Acton et al. 1992, Phillips 1994) or view the teaching of clinical skills as an inherent part of their teaching function (Webster 1990, Charlesworth et al. 1992). It would appear from the findings of this study that teachers remain in somewhat of a dilemma with regard to the future clinical role. Although they hope that there will be changes in the clinical role, they appear unconvinced that this will actually happen in practice. It could be argued that the time is ripe for nurse teachers to take a more proactive role in moving towards what is seen as the more desirable outcome, that of increasing their responsibility for the acquisition of clinical expertise amongst Project 2000 students.

Facilitating students to acquire clinical expertise presupposes that the teacher is clinically competent. The nurse teachers in this study expressed a lack of confidence in their clinical skills, although it was interesting to note that some felt able to work as a safe and efficient practitioner albeit in a role of less responsibility than that, say, of a ward sister or in some cases a staff nurse. There have been, and are currently, rapid developments within the area of nursing practice and it is questionable whether those teachers who have not maintained clinical responsibilities for patients/clients would be in reality safe practitioners.

Questions are raised concerning the level of competence required to act as a clinical role model in the practice setting. It could be argued that teachers 'cannot keep up with the practice, unless they are also in practice' (Jarvis 1992) and it has been commented that there is no general consensus of opinion on what clinical competence actually means in relation to the role of nurse teachers (Gerrish 1992). The respondents in this study suggested that some retention of clinical commitment was necessary for nurse teachers, and that part of that commitment should primarily be as a practitioner and not as a teacher.

It was also seen as desirable to develop strategies to ensure that the clinical expertise/experience of the nurse teacher corresponded with their clinical teaching/liaison role. This would appear to be a crucial element in the maintenance of clinical competence amongst nurse teachers, as to place a teacher in a clinical area with which she or he has had no recent experience as a clinical nurse would only serve to enhance the deskilling process. Ignoring the nurse teacher's past clinical experience devalues the potential role that the teacher could make in the clinical area. Other studies (Shaw 1994) have attempted to interpret clinical competence in relation to the nurse teacher, and the need to have the opportunity to practise in the specific clinical area as a nurse was emphasized.

\section{Lecturer/practitioner role}

It is interesting to note, however, that one of the main suggestions emerging from this study is to develop the role of the nurse teacher as a lecturer/practitioner. The level of clinical involvement that this role entailed was perceived to be at least $50 \%$ of the nurse teacher's time. This would appear to be a more reasonable stance to take with regard to clinical competence and credibility. It would, however, necessitate a financial commitment on the part of service for the nurse teacher's time. The ability to work smoothly as a member of the ward or community team requires a knowledge of the structures and processes within the institution or unit.

The current practice of 1 day per week clinical contact may not be a sufficient period of time to achieve this. Having the minimum commitment of 1 day may not support the teacher in the quest to really be treated as part of the organization that would, of necessity, involve managing and leading other members of the health care team. Effective management and leadership involves a knowledge of the nature and culture within the working environment.

Although the development of the lecturer/practitioner role was seen as desirable, it is perhaps somewhat disappointing to note that this was not seen as probable. This 
may relate to the finding that the workload of nurse teachers has increased greatly following the introduction of Project 2000, a finding consistent with that reported in other studies (Payne et al. 1991, Hardiman 1993, Hunter \& Houghton 1993). Perhaps the current difficulties that our respondents reported with regard to finding time to go on to the clinical area explains their pessimism for the future role of lecturer/practitioner.

This lack of time for a clinical commitment is one that has been identified previously (Clifford 1993). It would seem that there has not been an effort to prioritize this aspect of the nurse teacher's role from a strategic standpoint. The question remains, therefore, that if the structure and organization are not supporting a clinical commitment, why are nurse teachers not challenging this more vociferously?

\section{Acknowledgements}

This paper forms part of a study commissioned by the English National Board for Nursing, Midwifery and Health Visiting, entitled The evolving role of the nurse teacher in the light of educational reforms. The views expressed in this paper are those of the authors and not the Board.

\section{References}

Acton I., Gough P. \& McCormack B. (1992) The clinical nurse tutor debate. Nursing Times 88(32), 38-40.

Bedford H., Phillips T., Robinson J. \& Schostak J. (1993) Assessing Competencies in Nursing and Midwifery Education (Final Report). English National Board for Nursing, Midwifery and Health Visiting, London.

Charlesworth G., Kanneh A. \& Masterson A. (1992) The clinical nurse tutor debate. Nursing Times 88(32), 38-41.

Clifford C. (1993) The clinical role of the nurse teacher in the United Kingdom. Journal of Advanced Nursing 18, 281-289.

Crotty M. (1993) Clinical role activities of nurse teachers in Project 2000 programmes. Journal of Advanced Nursing $\mathbf{1 8}$, $460-464$.

Dale A.E. (1994) The theory-theory gap: the challenge for nurse teachers. Journal of Advanced Nursing 20, 521-524.

Dalkey N. \& Helmer O. (1963) An experimental application of the Delphi method to the use of experts. Management Sciences $\mathbf{9}$, 458-467.

Department of Health (1989) A Strategy for Nursing - A Report of the Steering Committee. DoH, London.

Department of Health (1993) Research for Health. DoH, London. Department of Health (1994) Nursing, Midwifery and Health Visiting Education: A Statement of Strategic Intent. DoH, London.

Ferguson K.E. \& Jinks A.M. (1994) Integrating what is taught with what is practised in the nursing curriculum: a multidimensional model. Journal of Advanced Nursing 20, 687-695.

Gerrish K. (1992) The nurse teacher's role in the practice setting. Nurse Education Today 12, 227-232.
Hardiman R.H. (1993) Teachers' experiences of their role following the implementation of Project 2000: a qualitative approach. Journal of Advanced Nursing 18, 1023-1032.

Hunter P. \& Houghton D.M. (1993) Nurse teacher stress in Northern Ireland. Journal of Advanced Nursing 18, 1315-1323.

Jarvis P. (1992) Theory and practice and the preparation of teachers of nursing. Nurse Education Today 12, 258-265.

Jowett S., Walton I. \& Payne S. (1994) Challenges and Change in Nurse Education - Study of the Implementation of Project 2000. National Foundation for Educational Research in England and Wales, Slough.

Luker K.A., Carlisle C. \& Kirk S. (1995) The Evolving Role of the Nurse Teacher in the Light of Educational Reforms (Final Report). English National Board for Nursing, Midwifery and Health Visiting, London.

National Health Service Management Executive (1993) A Vision for the Future: The Nursing, Midwifery and Health Visiting Contribution to Health and Health Care. DoH, London.

Osborne P. (1991) Nurse teacher and ward-based learning. Senior Nurse 11(4), 28-29.

Owen S. (1993) Identifying a role for the nurse teacher in the clinical area. Journal of Advanced Nursing 18, 816-825.

Payne S., Jowett S. \& Walton I. (1991) Nurse Teachers in Project 2000: the Experience of Planning and Initial Implementation. National Evaluation of Demonstration Schemes in pre-registration nurse education (Project 2000), Interim Paper No.3. National Foundation for Educational Research, Slough.

Phillips R. (1994) Providing student support systems in Project 2000 nurse education programmes - the personal tutor role of nurse teachers. Nurse Education Today 14, 216-222.

Rapport F. \& Maggs C. (1994) Project 2000 Nurse Education: the Service Perspective. Nursing Research Unit, University of Wales, Cardiff.

Royal College of Nursing of the United Kingdom (1995) REC Review Body Evidence. RCN, London.

Shaw J.T. (1994) How Can Educationalists Support Nursing Practice Development? The Institute of Nursing, The University of Leeds, Leeds.

Stewart D.W. \& Shamdasani P.N. (1990) Focus Groups: Theory and Practice. Sage, Newbury Park, California.

Strauss A. \& Corbin J. (1990) Basics of Qualitative Research: Grounded Theory, Procedures and Techniques. Sage, Newbury Park, California.

United Kingdom Central Council for Nursing, Midwifery and Health Visiting (1986) Project 2000: A New Preparation for Practice. UKCC, London.

United Kingdom Central Council for Nursing, Midwifery and Health Visiting (1994) The Future of Professional Practice the Council's Standards for Education and Practice Following Registration. UKCC, London.

Webster R. (1990) The role of the nurse teacher. Senior Nurse 10(8), 16-18.

White E., Riley E., Davies S. \& Twinn S. (1993) A Detailed Study of the Relationship Between Teaching, Support, Supervision and Role Modelling in Clinical Areas, Within the Context of Project 2000 Courses. English National Board for Nursing, Midwifery and Health Visiting, London. 